\title{
Social and Environmental Impacts of Development on Rural Traditional Arctic Communities: Focus on Northern Sweden and the Sami
}

\author{
Sonja H. Bickford ${ }^{1}$, Jon-Eric Krans ${ }^{2}$ and Nate Bickford ${ }^{3}$ \\ ${ }^{1}$ University of Nebraska Kearney, Kearney, NE, USA \\ ${ }^{2}$ University of Great Falls, Great Falls, MT, USA \\ ${ }^{3}$ University of Nebraska Kearney, Kearney, NE, USA
}

Correspondence should be addressed to: Sonja H. Bickford; bickfordsh@unk.edu

Received date: 1 September 2015; Accepted date: 3 December 2015; Published date: 29 January 2016

Academic Editor: Tahereh Alavi Hojjat

Copyright (C 2016. Sonja H. Bickford, Jon-Eric Krans and Nate Bickford. Distributed under Creative Commons CC-BY 4.0

\begin{abstract}
In the past few decades, the Arctic has become of keen interest for nations and developers around the world. This can be seen in the development of industries, establishment of Arctic centric organizations, as well as the expansion of the Arctic Council's membership. Countries with at least some part located above the Arctic Circle are; Norway, Greenland, Canada, United States, Russia, Finland, and Sweden. The focus on the indigenous people, specifically the Sami of Lapland, presents a good case for assessing impacts of development on northern, Arctic, communities. In Sweden, the population density is recorded as 21.4 people per square kilometer, with a higher population density in southern Sweden. The majority of the Sami people live in small to medium-sized communities, in remote regions, often resulting in a disconnect with the modern world. One industry that is already present in the Swedish Arctic is mining, especially for ore and carbon. However, now other industries, including multinational enterprises (MNE's), such as Facebook, which recently built a new five acre data center near the Arctic Circle, are beginning to realize the opportunities the Arctic region and its environment have to offer. Many are asking how sustainable is business development in the Arctic which can be answered by analyzing the impacts on the Sami communities and how people react and should react to these changes within their communities. This study analyzed current events through literature review and interviews of representatives from the impacted Arctic regions. The increased development has resulted in both negative and positive impacts such as reduction of land use, but increased employment opportunities.
\end{abstract}

Keywords: Arctic, Corporate Social Responsibility (CSR), Environmental Impact Assessment (EIA), Indigenous, Social Impact Assessment, Social Justice

Cite this Article as: Sonja H. Bickford, Jon-Eric Krans and Nate Bickford (2016), " Social and Environmental Impacts of Development on Rural Traditional Arctic Communities: Focus on Northern Sweden and the Sami," Journal of EU Research in Business, Vol. 2016(2016), Article ID 854073, DOI: 10.5171/2016.854073 


\section{Introduction}

Arctic regions can be defined in many ways. Arctic can mean anything above the Arctic Circle at 66 degrees or by the climate, lifestyles, and environmental characteristics. Through interviews conducted as part of the study in Sweden, it was found that the Arctic was defined as a harsher environment with colder temperatures than southern Sweden which has an impact on the vegetation, bio regeneration, and wildlife. In addition, many Swedes mentioned the sparse populated areas and accessibility as characteristics of the northern parts of the country and the areas of where the Sami communities lived and the active reindeer herding pasture grounds. In defining the Arctic and what it means, the Arctic can be defined and viewed as regions such as the high versus the low Arctic which goes beyond the definition of the 66 degree Arctic Circle. The Arctic is a rich, fascinating region with untouched wilderness, unusual climate, indigenous people, and amazing natural resources. Global attention has turned to the Arctic for some or all of these regions. This can be seen in the interest of other non-Arctic nations, such as China, Italy and the Republic of Korea, who have obtained observer status and are watching the Arctic council activities (Arctic Council, 2015). The Arctic regions are rich in natural resources such as coal, iron ore, cobalt, titanium, tungsten, gold, copper, and diamonds and rare earth gems to name a few. The natural resources in Sweden are minerals such as iron ore, copper, gold, silver, and tungsten. But also timber "trees that are grown in order to produce wood" (Timber, 2015), and hydropower "electricity produced from machines that are run by moving water" (Hydropower, 2015).

\section{Discussion}

Social justice can be defined as promoting a just society by challenging injustice and valuing diversity. It exists when all people, and society, share a common humanity and therefore have a right to equitable treatment, support for their human rights, and a fair allocation of community resources. In conditions of social justice, people are not to be discriminated against, nor their welfare and well-being constrained or prejudiced on the basis of gender, sexuality, religion, political affiliations, age, race, belief, disability, location, social class, socioeconomic circumstances, or other characteristics of background or group membership" (Toowoomba Catholic Education, 2006). Social justice in the indigenous communities has become an issue with the economic development occurring in regions containing indigenous groups. This has both positive and negative impacts. The benefits include new infrastructure such as telemedicine, distance education, new technologies (Nordforsk, 2015). Detrimental impacts on the indigenous communities can be potential loss of land use, natural resources, grazing ground accessibility for reindeer herding, and substance lifestyles as well as the influence of modern lifestyles, as well as amenities countering the traditional lifestyles of the communities (Huntington and Fox, 2005). As Wohlberg (2013) states, the people of Northern Sweden have made it known that they will no longer remain silent while developers, such as oil companies, destroy their native land. It has been suggested that sustainability be assessed on a wide scale as it can impact many aspects of the community from land, water, air, to the people and society present in the impacted community. Thus, Ness, et. al. (2007) suggested that the understanding of sustainability assessment from the environmental-focused realm to a wider interpretation of sustainability should be done in cases of large development projects to fulfill a spatial focus from nature-society as an integrated system as impacts can and will impact more than one area of the system.

\section{Literature Review}

In assessing impacts from large scale industrial developments, developers are required to conduct and submit an environmental impact assessment prior to applying and obtaining the required permits 
to initiate the project itself. This Environmental Impact Assessment (EIA) was signed into law by President Nixon on January 1, 1970. The act set forth a vision for change as it acknowledged decades of environmental neglect from human impacts. The law was established to maintain conditions under which man and nature can exist in productive harmony (NEPA, 2015). The law charged the Environmental Protection Agency (EPA), under Section 309 of the Clean Air Act, to review the environmental impact statements (EIS) of other federal agencies and to comment on the adequacy and the acceptability of the environmental impacts of the proposed action (NEPA, 2015). In Sweden, the EIA has gradually been implemented and has resulted in provisions for EIA to be included in more than 20 different acts. The overall Swedish objective is to increase the consideration of environmental and management issues in decision-making (National Board of Housing, Building, and Physical Planning et al., 1997). The current Environmental Code (Miljöbalk) is based on the EC Directive 85/337/EEC (97/11/EC).

Sustainable development has been discussed in the past decade, but more recently has been a common topic in discussions focused on Arctic development. The standard definition provided by the Brundtland Commission is "to make development sustainable - to ensure that it meets the needs of the present without compromising the ability of future generations to meet their own needs" (WCED, 1987), and the U.S. National Research Council (1999) defines sustainable development as having three important components: what is to be sustained, what is to be developed, and the intergenerational component. Ness et. al (2007) add to these definitions by stating that the three key ideas to be developed are people, society, and economy. In Sweden, responsible and sustainable development is defined by the Swedish EIA legislation, or miljökonsekvesbeskriving (MKB), as achieving a balance or goals in the ecological, economical, and social development in a way that does not destroy opportunities for future generations. Many agree that the benefits of responsible development for businesses will result in success when applying for permits to operate such as the environmental impact assessment process and by conducting additional social impact assessments. More specifically taking on actions of community buy-in into the company and its proposed projects, the company will gain what is called a social license to operate (SLO), not to mention the benefits to the environment as well as society and stakeholders as issues can be addressed in the planning stage and mitigated by the project lead/developer.

Social impacts are measured in the social impact assessment (SIA), which, depending on the country's environmental code. In some countries the SIA is a required part of the environmental impact assessment (EIA), while in others it is not. It also varied to what extend social impacts are assessed by country. In the United States the environmental impact process is defined by NEPA (or Environmental Impact Statement (EIS) and this legislature defines what social impacts must be assessed in projects that have significant impacts on the environment such as mining, oil, gas and larger development structures. In the European countries, including Sweden, it is the Environmental Code that regulates the development process (EU, 2015).

The Sami are the indigenous people living in the Barents region. There are approximately 40,000 Sami in Norway, which is approximately $1 \%$ of the country's population and 20,000 in Sweden, representing $0.2 \%$ of the population (National Sami Information Centre, 2005). The presence of the Sami population encourages collaboration and communication, especially if the activities or proposed projects involve impacts or activities related to reindeer husbandry, tourism, language and culture. Reindeer husbandry is a traditional Sami occupation and lifestyle, which has been historically affected by the creation of national borders and seriously threatened by the development 
of extractive industries and tourism (Berlina, et. al, 2005). The reindeer and the Sami reindeer herders migrate between different areas of the northern parts of the country and even across national borders.

The Sami people have a long and rich history, with evidence of settlement in the arctic region of Sweden for thousands of years. Low population density and the geographical location have resulted in a disconnection from the modern business world for the Sami. "The Sami population is estimated at around 80,000 people, 20,000 of them live in Sweden. Since the Sami have been recognized as an indigenous people, they have the right to preserve and develop their crafts, language, education, reindeer husbandry, traditions, and identity" (Sami in Sweden, 2015). In the 1950's, the Sami associations were established, and with it came a big push for increased influence and independence for the Sami, which they had been struggling with for a long period of time. 'Sametinget', or the Sami Parliament, which is its own parliament separated from the Swedish one, consists of eight political parties. The main duties the parliament has is to "safeguard, develop, and coordinate all matters concerning Sami areas of interest such as hunting, fishing, reindeer herding (which include compensation for damage caused by predators), and Sami language and culture" (Sami in Sweden, 2015). The Sami struggled for a long time for independence, while being an "invisible minority". The strengthening of the political power, especially with the establishment of the Sami Parliament (which was as late as 1992 in Sweden), seem to have nullified this invisibility. For the few Sami who are still involved in reindeer herding, the concerns are huge. The most obvious threats for the reindeer herders are climate change, predators, and land use. Conflicts regarding land use are numerous and complex. The construction of hydro-electric dams and the submergence of land, by the construction of roads and high-voltage transmission lines, by the advance of the lumber companies, mines, and recently, by the development of infrastructure for wind power and data centers such as the Facebook data center in Luleå in northern Sweden are all factors for destruction or access to pastures critical for the survival of the reindeer. Facebook's data center was built in 2011 and it was the first data center Facebook ever built outside of the U.S. Although an official price was never given for the investment, Luleå officials have estimated construction costs of up to $\$ 760$ million USD and with an estimated of 4,500 new jobs will be created during a 10-year period (Macguire, 2014). The reason for the location choice for the new datacenter was due to Luleås location. The town is about 60 miles south of the Arctic Circle with an annual average temperature of $2.04^{\circ} \mathrm{C}\left(35.7^{\circ} \mathrm{F}\right)$. With new innovative technological solutions, the high-performance servers and computers, they will simply "chill" themselves using the air from the cold and harsh climate right outside. They will be able to do so for 8 months out of the year, and for the remaining 4 months the datacenter will use hydropower as its main source of energy. This new way of keeping the servers and computers cool makes Facebook's data center in Luleå around $30 \%$ more cost effective compared to other data centers of its kind (Macguire, 2014). Similar trends are happening in surrounding countries, such as Google's new center in Finland.

There are both positive and negative impacts from this data center. The main negative impacts come from the reduction of land and the impact on the rivers. The initial and first data center that was built is about 300,000 square feet and two more equally large buildings will be built, out of which one is already under construction. The estimated plant's land use footprint is roughly 900,000 square feet. In cases such as this the footprint is an impact on land. Land areas in northern Sweden is being impacted by built development, which in turn directly impacts the reindeer as their grazing area is decreasing and inadvertently the Sami reindeer herders and their livelihoods. In addition, the impact of additional members to the communities brings access to new educational and training opportunities in addition to jobs. Also, new cultures and 
customs with different ways to communicate and engage in communities emerge with the influx of new people within a community. However, in this case the positive impacts far exceed the negatives. Since the establishment of the data center in Luleå, it has already created 900 direct jobs and generated SEK 1.5 billion (roughly $\$ 225$ million USD) in domestic spending (Macguire, 2014 and Sverdlik, 2014). The projects overall economic impact in the country has been about SEK 3.5 billion (roughly $\$ 524$ million USD), and by 2020 the numbers are up to SEK 9 billion (roughly $\$ 1.35$ billion) of economic impact in Sweden and over 2,200 jobs created (Sverdlik, 2014). The question remains: who will take advantage of the opportunities?

About 25 years ago, Scandinavian countries prioritized growth, export, and employment for the minority people of the Sami. Even though the influence of the Sami's political weight has increased over the last two to three decades, it still does not ensure them ownership nor control over natural resources (Glomsrod and Aslaksen, 2009). To better understand the situation in Sweden, it can be looked at through the situation of Kiruna. Kiruna is located in northern Sweden, above the Arctic Circle, and has been a mining town since the late 1800s, in 1899 when the mine opened there were only 18 people officially registered as citizens. Today, the population of Kiruna is above 23,000 (O'Sullivan, 2014). In addition to the mine, the area provides grazing and herding areas for the reindeer and reindeer herders. The main mine in Kiruna is the iron ore mine. It has been and still remains as the main industry in Kiruna and the region. Kiruna has depended on the mining industry for economic development. When the industry blooms, the population will increase due to more employment opportunities that are created. In contrast, when the industry economy drops, it cuts off employees who have to leave the city for a living. With such a long history of mining, Kiruna is now being swallowed by the earth underneath it. If the extraction is to continue, the mine must burrow to a depth of 1.3 kilometers, so far beneath the earth on which Kiruna stands that the town's very foundations are at risk (O'Sullivan, 2014). Kiruna faced a stark choice to give up on the mine or move the city itself (O'Sullivan, 2014). Even though other industries such as tourism have become more popular in the region, the iron ore industry has been, and is still, the main economic driver in Kiruna. 49 percent of Kiruna's men are working in the mine in skilled, well-paid work to boot. The impacts of the mining industry have been extreme for Kiruna. Working in a mine is considered a high-risk job, thus the pay is good and has resulted in a stable, upright local economy. It also increases job opportunities which have resulted in the growth of northern towns, such as Kiruna. The current plan is to move the city about two miles to the east, meaning that Kiruna residents now have to leave their homes and rebuild. But with the iron ore industry being such a big part of Kiruna's local economy, it came out as a simple economic calculation of costs and benefits to the community. Moving of the mine was the logical choice. Shutting down the operation would potentially crush the economy and society of the city. Kiruna is already facing the issue of people leaving the city, especially in the younger generation between 20 and 30 years of age. In addition many females are migrating out of these northern areas due to the lack of jobs. With the main industry, iron ore extraction, being so male dominant, the community offers less skilled work for women. The case provides an example of what is now the most drastic and bold example of impacts on the environment and society from development, moving a whole city. This could very well become a design for other settlements forced to consider moving because of environmental or economic reasons. The project will be quite spectacular as the ground covered in a century will be remarkable, but the place will not change that radically from day to day (O'Sullivan, 2014). The evacuation from the old city is projected to begin in 2018. If all goes as planned, by 2023 , the new midpoint will have been constructed just to the east of the current town, toward which people will be moved from the former central core and by 
2028, the streets around this new city center will be filled with apartment buildings and finally by 2050 , the clearing will be done, and the shift of residents will have largely been completed (O'Sullivan, 2014).

This case provides a great example of the impacts of economic development on the environment, both flora and fauna, as well as the clear impacts on an entire society and nearby regions as well, which depend on the town. The adaption of development opportunities for growth, or in this case the change required of existing ones as well as the consideration of the land use for traditional uses, such as reindeer grazing lands or recreational uses is key. Examples of new industries and businesses in the region are tourism and new technologies. It should be noted that one of the biggest reasons for this is the world famous ice hotel in the nearby village Jukkasjärvi. It is estimated that the ice hotel attracts over 100,000 people to the area every year. However, the tourists that visit the ice hotel rarely bother to make the 15-minute drive to visit Kiruna (Kinder, 2014). This is another factor that the project has to fulfill. With such a large number of visiting tourists only 15 minutes away from the city, by creating a more densely built, lively city that can exist independently of its namesake mine, the tourists visiting the ice hotel, might potentially visit Kiruna as well during their stay. Consumer spending would increase and boost the local economy. This could decrease the loss of the younger generation. Another entity present in Kiruna, which will attract tourists, and also create job opportunities, is Spaceport Sweden. In the last wilderness areas of Europe, Spaceport Sweden is working to establish a state of the art, futuristic, facility worthy of being Europe's gateway into space. Active in the development of commercial manned space flight since 2005, Spaceport Sweden (Seedhouse, 2014) is today one of the most established players in the dynamic international space industry. The tourism aspect of Spaceport Sweden includes parabolic flights, northern lights flights, and spaceflight training. It is estimated that combined, the ice hotel, visiting of the world's biggest iron ore mine, and space tourism through Spaceport Sweden, would attract about 145,000 visitors per year as Spaceport (2015) estimates. With the economic growth potential, the issues of social justice, environmental sustainability of the development and influx of people to the area, and the impacts on the society and community, reindeer herders as grazing lands must be addressed in addition to the current local community and their benefits and consequences of the plans.

\section{Research Question}

According to the estimates by the Lapland Chamber of Commerce (2013), investments worth tens of billions of euros are expected in the northern regions of Finland, Norway, Sweden, and Russia in 2013-2017. The main investments are associated with projects in the oil and gas industry, mining industry, hydro and wind energy, and bio and nuclear energy (European High North business Yearbook, 2013). This is a growth trend for investments into the Arctic region which will include new large scale developments, which in turn will impact the environment, but also the local population and community inhabiting those regions.

The aim of the study was thus to gain a better understanding of the impacts of development on indigenous communities and thus the main focus and question of the study was why the increased interest in the Arctic. In addition, we assessed the potential impacts, both positive and negative, of development in the fragile Arctic regions on a larger scale, and more specifically wanted to answer the question of these issues in northern Sweden.

The Arctic region has moved to the center of world politics in 2014, due to the energy security agenda of the Arctic countries as well as most East Asian countries, including China and Japan (Pourzitakis, 2014). The Arctic council which was created in 1996, has matured from a largely symbolic organization to one addressing the quickening pace and consequences of development and climate change in the Arctic 
by creating a legally binding agreement on oil spill response, search and rescue operations, as well as dealing with environmental sustainability and natural resource security issues with the interest in developing the Arctic's natural resources (Myers, 2013).

In 2012, the Arctic sea ice reached its lowest point ever, which triggered very real fears about climate change, but it has also transformed the region into an energy hotspot. The Arctic is believed to contain 30 percent of the world's undiscovered gas and 13 percent of its undiscovered oil. That Japan would have an interest in the Arctic should come as no surprise, given its scarce natural resources and its reliance on imports for about 84 percent of its energy needs. At the same time, the Northern Sea Route through the Arctic offers an alternative passage for energy transportation, offering both energy importers and exporters the opportunity to reduce their dependence on unstable waterways such as the Strait of Hormuz and the Strait of Malacca (Pourzitakis, 2014). In May 2013, at the Kiruna Meeting of the Arctic Council, Japan, China and South Korea were three of the six admitted as permanent observers to the Arctic Council, enabling them to sit in on meetings and promote their own Arctic strategies (Myers, 2013). Of these three countries, China has been particularly active in pursuing economic, political and scientific initiatives. These actions prove that there is global interest in economic and political endeavors in the Arctic region.

\section{Research Design and Methodology}

This study has been conducted by analyzing current events in the Arctic region through a literature review and interviews of representatives from the impacted Arctic region in Sweden during the spring of 2015. Those interviewed for this study included environmental consultants, governmental agency representatives, company decision makers, representatives from Sami organizations, and academic researchers. The interviews were conducted in 2014-2015 and consisted of semi structured questions and were conducted both face-to-face as well as via distance using email and Skype. Those interviewed were from the Northern region of Sweden. The study analyzed definitions of social justice, particularly focusing on the justice of indigenous groups and even more specifically of the Sami in Sweden. Alongside with the definitions in current literature about social justice and sustainable and responsible development, future forecasts were assessed to better understand the projected growth and impacts in the Arctic regions from planned development projects.

The aim was to gain a better understanding of the impacts of development on indigenous communities. The development trends and their impacts on the Arctic communities were assessed and analyzed by studying two case examples in Sweden as well as through interviews with representatives from private and public sectors as well as indigenous organizations.

\section{Result Discussion}

The higher standards, in regards to assessing the impacts of development on both the environment and the social community, are being brought on by the liability of foreignness, where foreign developers build projects in countries thus raising domestic expectations and practices. This has an impact on both regulations as well as best practices trickling through the industry and into other industries as an example of good practices with successful outcomes. For example, it was found that the practice of byggdemedel, which can be defined as payments from the mining industry and now wind energy developers to the local community as a token for community development, is an example of volunteer practice which is now trickling down as an example and even expectation into other development projects and industries. Developers have started to see the benefits of building long term relationships with local impacted communities, as mining has done for a much longer time. Other examples of sustainability in Sweden are remediation and mitigation plans for mines that are conducted long term so that the mine is returned to the 
original state. The mine cannot, in Sweden, be converted to an alternative purpose as it has been done in other parts of the world. For example, mine sites have been converted to museums and education centers, visitor attractions, recreational areas, gardens or parks, or fish farms (Mining Facts, 2015).

It has also been noted in Sweden that social impact assessments (SIA) would be useful for developers and public decision makers in determining the nature of impacts on the people within the community. The social license to operate (SLO) is key to building the relationships between local communities and organizations. The field of management science states that collaboration and cocreation of projects typically have a more successful and positive outcome for all parties as input into the final decision is shared and can be influenced (Burdge, 1990). This study found that social impacts, as part of the EIA, in Sweden are mainly focused on health concerns, not social issues. In addition, examples of some impacts on communities are the influx of more people from outside the community, new or additional job and training opportunities, access to more goods and services, infrastructure support for community in community (public) services. Some of these key issues are already addressed in the EIAs conducted, but they lack consistency in terms of what is or should be addressed. In addition, the question of what should or must be communicated to the general public and stakeholders during the EIA public comment periods are in most cases done well, but could be improved. For example, the city of Lulea has funded a project which will develop a handbook that addresses the questions of communicating with local communities, and more specifically the indigenous, or Sami, communities of northern Sweden (Nenasheva, et. al, 2015). Some rural communities are growing as we see in the case with Kiruna. Some towns and cities are vibrant, they bring opportunities that did not exist before, but also threats and influences from the outside. Threats come from western or foreign influence as new people enter the areas and create new expectations on the people and the society.
There may be a loss of traditions, culture, and language, not to mention land use, as has been experienced by the Sami. It has been found through the literature review and the interviews that the consensus between stakeholders is the desire to work together and be listened to and that working collectively and collaboratively for a common good for all parties and thus the goal is to bring the most benefit to all stakeholders of the community.

\section{Study Limitations}

The current study of the impacts from large corporate development on Indigenous communities in the Arctic specifically focusing on the social justice and sustainability for the Swedish Sami was conducted as part of a small scale, shortterm, strategic project, in preparation for continued work in the field. Additional research into a larger scale study of the identified region, whether the Scandinavian countries, Barents, or all eight Arctic countries, should be conducted in addition to having a larger sample. This would be beneficial in comparing the findings from this study in addressing whether the results would be similar and sharing of the results or lessons to be learned. The study finds that the case of Kiruna in Sweden is an example of a modern, current, issue in terms of environmental and societal impacts that integrate the impacts on a community (nature-human), system, as a whole. It can be stated that the current study's sample size and area, while of great interest, is small. In addition, the interviews concluded to gather data from the region, while good in regards to collecting the crucial information as well as additional information that the interviewed company representatives would give, worked well during the face to face interviews, but were not as formal or lacking information when conducted via phone or email. Thus, it would be recommended and beneficial to conduct additional and future data gathering or fact finding trips in person. 


\section{Conclusion}

Social license to operate is defined as an acceptance of a development or developer's proposed project by the impacted community, and social justice is defined as promoting a just society by challenging injustice and valuing diversity. Analyzing the social justice and social license to operate (SLO) in Northern Sweden, and the Arctic region, both which have a long history of indigenous communities and traditions is a very timely issue as the Artic in general is facing a growing trend of development of the land and communities. Based on the literature review, the development trends, and the example of Kiruna, as well as the presence of indigenous communities in the region has increased the need for involvement of these local and traditional stakeholders in development projects through the Arctic regions. The developers, in many cases, have taken it upon themselves to engage and communicate with the public as well as make themselves a part of that local impacted community by offering their support. This is a way to obtain a social license to operate, meaning acceptance from the community for their presence and operations. This practice of going above and beyond the legal requirements of the environmental or social impact legislation and regulation is seen and defined as the area of corporate social responsibility and in regards to social justice it is often maintained and remains positive as long as there is open communication and support for activities conducted by the other stakeholders in the community. In addition, the study has found that developers must go above and beyond and make themselves a corporate citizen of the community that they will operate in to build trust and communication channels, and find ways to operate and communicate which are in line with the existing community structure and expectations. It was concluded that additional and further study needs to be done in the area of development in rural areas, such as the Arctic and the stakeholders, i.e. the members of the societies in the Arctic regions. In addition, further study of long term environmental impacts and changes will be important components to help develop best management and practices of economic development in the Arctic. It was also suggested that the costs and benefits of environmental and social impacts assessments and CSR should be studied further to aid decision makers in both the communities as well as in the industries considering initiating business in these remote, Arctic, regions.

\section{Acknowledgment}

The authors would like to acknowledge the University of Lapland's Arctic Centre for their support and contribution, specifically the Northern Institute of Minority and Environmental Law (NIEM), as well as the University of Nebraska Kearney and the University's College of Business and Technology (CBT) for their support of the work.

\section{References}

1. About EIA and Environmental Assessment (2014) SLU. [Online] [Retrieved September 25 2014],

2. Arctic Council (2015) Arctic Council. [Online] Arctic Council [Retrieved on August 1, 2015], http://www.arctic-council.org/

3. Berlina, A., Hörnström, L., Diş, A. T., \& Fors. (2005) Case Study Report: KirunaNarvik (KINA) region. [Online] Nordregio [Retreived on Aug 22, 2015], http://www.nordregio.se/Global/Research/ EUROBORDERREGIONS/KINA\%20Nordregio .pdf

4. Biofuels. (2015) Definition: Biofuels. [Online] Investopedia. [Retrieved on March 26, 2015$]$, http://www.investopedia.com/terms/b/biof uel.asp

5. Burdge, R. J. (1990, March) The benefits of social impact assessment in Third World 
development. Environmental Impact Assessment Review. 10(1-2), 123-134.

6. Ecotoursim (2015). Definition: Ecotoursim. [Online] Reference.com. [Retrieved on March 26, 2015], http://dictionary.reference.com/browse/eco tourism

7. Ejdemo, T., Söderholm, P. (2011, March) Mining investment and regional development: A scenario-based assessment for Northern Sweden. Resources Policy. 36(1), 14-21.

8. European Union EIA Directive (85/337/EEC). [Online] European Commission [Retrieved April 2 2015], http://ec.europa.eu/environment/eia/eialegalcontext.htm

9. Hilden, M., Valve, H., Jonsdottir, S., Balfors, B., Faith-Ell, C., Moen, B., Peuhkuri, T., Schmidtbauer, J., Swensen, I., and Tesli, A., (1998) EIA and its applications for policies, plans and programmes in Sweden, Finland, Iceland, and Norway. Temanord. Nordic Council of Ministers. ISBN 92-893-0234-8.

10. Hanna, P., and Vanclay, F., (2013). Human rights, indigenous peoples and the concept of Free, prior and Informed Consent. Impact Assessment and Project Appraisal. 31(2), 146--157.

11. Hedlund, A. and Kjellander, C., 2007. MKB: Introduktion till miljökonsekvensbeskrivning [Introduction to describing environmental impacts]. Studentlitteratur.

12. Holder, J. and Lee, M. (2007) Environmental Protection, Law and Policy: Text and Materials. Second Edition. Cambridge: Cambridge University Press.

13. Huntington, H., and Fox, S. (2005) Arctic Climate Impact Assessment. Chapter 3: Changing Arctic: Indigenous Perspectives (pp. 61-98) Cambridge University Press.
14. Hydropower (2015) Merriam-Webster Dictionary. [Online], [Retrieved February 20, 2015], http://www.merriamwebster.com/dictionary/hydropower

15. Kinder, T. (2014). Kiruna: How to move a town two miles east. [Online]. BBC News. [Retrieved on March 30, 2015], http://www.bbc.com/news/magazine-

26447507

16. Myers, S. L. (2013, May) Arctic Council Adds 6 Nations as Observer States, Including China. [Online]. The New York Times. [Retrieved on May 15, 2015], http://www.nytimes.com/2013/05/16/worl d/europe/arctic-council-adds-six-membersincluding-china.html?_r=1

17. Nenasheva, M., Bickford, S., Lesser, P., Kankaanpaa, P., and Koivurova, T. (2015) Legal tools of the public participation in the Environmental Impact Assessment process and their application in the countries of the Barents Euro-Arctic region. Journal of Barents Studies. 1(3), 13-35.

18. Macguire, E. (2014 November) Can Scandinavia cool the internet's appetite for power? [Online] CNN [Retrieved on November 15, 2015], http://www.cnn.com/2014/11/14/tech/dat a-centers-arctic/

19. Minerals (2015). Definition: Minerals. [Online] Reference Dictionary. [Retrieved on March 29, 2015], http://dictionary.reference.com/browse/mi neral

20. Mining Facts (2015) Mining Facts: Potential uses of mine sites following mine closure. [Online] Mining Facts [Retrived on August 20, 2015], http://www.miningfacts.org/Environment/ What-happens-to-mine-sites-after-a-mine-isclosed/

21. Ness, B., Urbel-Piirsalu, E., Anderbord, S., and Olsson, L. (2007, January) Categorizing tools for sustainability assessment. Ecological Economics. 60(3), 498-508. 
22. Nordforsk (2015). Responsible Development of the Arctic. Proposal Call. [Online]. Nordforsk. [Retrieved on March 4, 2015], www.nordforsk.org

23. O'Sullivan, F. (2014, December) The City That Is Moving Down the Road. How to Reassemble a Place In 100 Years or Less. [Online] Nextcity. [Retrieved on March 30, 2015],

http://nextcity.org/features/view/the-citythat-is-moving-9-kilometers-down-the-road

24. Pourzitakis, S. (2014, February) Japan and Russia: Arctic Friends. Increasingly close ties offer both countries potential benefits in the Arctic and elsewhere. [Online] The Diplomat. [Retrieved on March 30, 2015], http://thediplomat.com/2014/02/japanand-russia-arctic-friends

25. Rautajoki, T., ed., (2013). European High North business yearbook. Lapland Chamber of Commerce.

26. Riksbank (2015) [Online] Riksbank. [Retrieved on March 20, 2015], www.riksbank.se

27. Soneryd, L. (2002) Environmental conflicts and deliberative solutions? A case study of public participation in EIA in Sweden. Doctoral Thesis. Örebro universitetsbibliotek. ISBN: 91-7668-317-6.

28. Glomsrod, S, and Aslaksen, I. (2009, November) The Economy of the North. Statistics Norway. [Online] Oslo Kongsvinger. Statistics Norway. [Retrieved on March 23, 2015], http://www.ssb.no/a/english/publikasjoner /pdf/sa84_en/kap3.pdf

29. Sami in Sweden (2015) Sami in Sweden. [Online] Sweden, Official site of Sweden. [Retrieved on August 20, 2015], https://sweden.se/society/sami-in-sweden/
30. Seedhouse, E. (2014) Suborbital: Industry at the Edge of Space. Springer Praxis Books. Springer Publishing, Switzerland.

31. Spaceport (2015) Spaceport Sweden. [Online] Spaceport Sweden. [Retrieved on August 1, 2015], http://www.spaceportsweden.com/

32. Sverdlik, Y. (2014) Study: Facebook's Luleå Data Center Boosts Local Economy. [Online] Data Center Knowledge. [Retrieved on March 30, 2015], http://www.datacenterknowledge.com/arch ives/2014/07/01/study-facebook-datacenter-in-lulea-boosts-local-economy

33. Timber (2015) Merriam-Webster Dictionary. [Online], \{Retrieved February 20, 2015], http://www.merriamwebster.com/dictionary/timber

34. U.S. National Research Council (1999) U.S. National Research Council. Our Common Journey: a transition toward sustainability. National Academy Press, Washington DC (1999)

35. Vanclay, F. (2003, March) International Principles For Social Impact Assessment. Impact Assessment and Project Appraisal. 21(1), 5-11.

36. Waugh, R. (2011, October) That's really cool: Facebook puts your photos into the deep freeze as it unveils massive new five acre data center near Arctic circle. Daily Mail. [Online] Dailymail. [Retrieved on March 9, 2015],

http://www.dailymail.co.uk/sciencetech/arti cle-2054168/Facebook-unveils-massivedata-center-Lulea-Sweden.html

37. WCED (1987) Our Common Future. Oxford University Press, Oxford. 